\title{
SYNTHESIS AND CHARACTERIZATION OF METHYL AMINO POLYSTYRENE AS RESIN MATERIAL OF CHROMATOGRAPHY
}

\author{
Herman $^{1,2,3,}{ }^{*}$, Anni Anggraeni ${ }^{1,3}$, Abdul Mutalib ${ }^{1,3}$, and Husein H. Bahti ${ }^{1,3}$ \\ ${ }^{1}$ Chemical Analysis and Separation Laboratory, Departement of Chemistry, \\ Faculty of Mathematics and Natural Sciences, Universitas Padjadjaran, \\ J1. Raya Bandung-Sumedang Km 21, Jatinangor, West Java, 45363 Indonesia \\ ${ }^{2}$ Departement of Pharmaceutical Chemistry, \\ Pharmaceutical Research \& Development Laboratory of FARMAKA TROPIS \\ Pharmacy Faculty, Universitas Mulawarman, Samarinda, \\ East Kalimantan, 75119 Indonesia \\ ${ }^{3}$ Biomolecular Laboratory, Departement of Chemistry, \\ Faculty of Mathematics and Natural Sciences, Universitas Padjadjaran, \\ J1. Singaperbangsa, Bandung, West Java, 40132 Indonesia \\ *Corresponding author: herman@ farmasi.unmul.ac.id
}

\begin{abstract}
Ion-exchange chromatography has been widely used in various separation process and purification. Commercial ion-exchange resin mostly uses polystyrene as base. This study reviewed the synthesis of cation-exchange resin with polystyrene as starting material. Polystyrene must be activated in order to make one of aromatic carbon chains being able to be binding with acetamide n-hidroxymethyl electrophilic. Polystyrene activation was conducted through two stages, i.e. (1) the formation of amidomethyl polystyrene (AMDP), and followed with (2) hydrolysis of acyl group. The activation of polystyrene generated white methylamino polystyrene (MAP) resin, of which its characterization used spectrophotometry UV, Fourier Transform-Infrared (FTIR), and density of MAP resin confirmed by pycnometer. The results showed that the characterization of FTIR and spectrophotometer UV for AMP exhibited the forming of primary amino group and disappearance of spectrum band of $\mathrm{C}=\mathrm{O}$ group at $3374.52 \mathrm{~cm}^{-1}$ with $\lambda_{\max } 230 \mathrm{~nm}$, the average of density of AMP resin sample was $1.7158 \mathrm{~g} / \mathrm{mL}$.
\end{abstract}

Keywords: Cation-Exchange Resin, Methylamino Polystyrene

Submitted on: 5 December 2018

Accepted on: 30 December 2018

DOI: https://doi.org/10.25026/jtpc.v4i4.204

\section{INTRODUCTION}

Ion-exchange chromatography is an easy separation method and highly used to separate and determine organic and inorganic ions in a mixture, so that it has been widely used either in laboratory or 
industry. In general, starting material which is used for fabrication of ionexchange resin is polymer, either natural or synthetic polymer [1]. The use of polystyrene as resin has been developed for increasing the efficiency of peptide synthesis as polymer with very good mechanic stability which is from polystyrene divinylbenzene [2].

The separation and purification can be conducted with ion-exchange chromatography method, because theoretically it has a high separation power. Ion-exchange chromatography method requires a big quantity of resin. While resin has high price, so it may be one of constrains in the financial sector. The expensive price of resin is caused by the comparable with complexity of its fabrication. Therefore, a renewable innovation is needed through home-made resin.

Fathy $[3,4]$ reported that resin or ion-exchange polymer was a small undissolved matrix, generally white or yellowish white, fabricated from organic polymer substrate. Ion-exchange resin was well-known as chelating resin. Typical characteristic of resin is as ionic component which is able to separate selectively in separation process or purification.

Ion-exchange resin is a stationary phase that is used at column of ion chromatography. Ion chromatography offers an easy separation method and trusted for separating and determining organic and inorganic ions in a mixture [5]. Separation obstacle in ion-exchange chromatography at opened column is requiring the big amount of resin with high price, so that many scientists have been doing research regarding the fabrication of ion-exchange resin using polymer as starting material, either organic or inorganic polymer.

Resin fabrication in this study was conducted through two stages, i.e. (1) the formation of amidomethyl polystyrene (AMDP), and followed with (2) hydrolysis of acyl group from AMDP to be MAP. The consideration why polystyrene was chosen as matrix was because polystyrene was polymer which has good electricity, high heat stability, thermoplastic solid, and ecofriendly.

\section{MATERIALS AND METHOD}

\section{Materials}

Chemicals used in this study were purchased from Sigma Aldrich and Merck such as: boric acid, chloride acid, ammonia, nitric acid, trifluoroacetic acid, n-hidroxymethyl acetamide, dichloroethane, dimethylformamide (DMF), ethylene glycol, hydrogen peroxide, potassium bromide, methanol, methylene chloride, sodium hydroxide, polystyrene of DVB 1\%, and tetrahydrofuran.

\section{Polystyrene Activation to be Resin of Methyl Amine Polystyrene}

\section{Fabrication of Acetamidomethyl Polystyrene}

1.0 gram of divinylbenzene (DVB) polystyrene $1 \%$ was dissolved with $10 \mathrm{~mL}$ dichloroethane (DCE). Then, the mixture was added with $0.5 \mathrm{~mL}$ (10 drops) nhydroxymethyl acetamide and $2.5 \mathrm{~mL}$ trifluoroacetic acid (TFA) successively, afterwards refluxed about 22 hours. The reflux result was cooled at $26^{\circ} \mathrm{C}$ and centrifuged. Precipitation was washed gradually with tetrahydrofuran (THF), DMF: aquadest (3:1), DMC, and methanol. The precipitation was vacuumed by using desiccator and freeze dryer until gained the white precipitation of AMDP.

\section{Hydrolysis of Acyl group}

The AMDP precipitation was added with $5 \mathrm{~mL}$ ethylene glycol and stirred at 26 ${ }^{\circ} \mathrm{C}$. While stirring, the mixture was added 
with $5 \mathrm{~mL} \mathrm{HCl} 35 \%$ successively and refluxed at $110^{\circ} \mathrm{C}$ for 22 hours. The result was cooled at $26^{\circ} \mathrm{C}$ and centrifuged to get a yellow solution. The yellow solution was washed successively with THF: $\mathrm{NaOH} 1 \mathrm{~N}$ (3:1), THF: aquadest (3:1), THF, and methanol. The gained white filtrate was vacuumed by using desiccator and freeze dryer, so being gained MAP.

\section{Characterization using FTIR}

Approximately $1 \mathrm{mg}$ of the AMDP precipitation was added with dry potassium bromide sufficiently. The mentioned solid was crushed using mortar so gaining pellet. The pellet was analyzed by using spectrophotometry FTIR. Same procedure was employed for MAP characterization.

\section{Characterization using Spectrophotometer UV}

The analysis using spectrophotometry UV was conducted by dissolving polystyrene into ethylene glycol solvent with concentration $10 \mathrm{ppm}$ then analyzed using spectrophotometer UV. Same procedure was employed for MAP characterization in DMF solvent with concentration $10 \mathrm{ppm}$.

\section{Determination of Density of MAP Resin}

Pycnometer was washed, dried, and weighed until gaining constant result of the weighing in an empty state. Then, the pycnometer was filled with distilled water, and weighed again. Temperature of distilled water was measured. The pycnometer was dried again, then entered by resin, and weighed. After that, the pycnometer was filled by distilled water until densely, and weighed again. Temperature of distilled water was measured.

\section{RESULTS AND DISCUSSION}

Polystyrene activated can generate methyl amino polystyrene. MAP resin is a white resin with soft texture that is hard to dissolve in among organic, inorganic, or acidic solvent. This is because MAP is a polymeric resin which has many double bonds and big molecular weight that causes difficult to dissolve (shown in Figure 1).

The first step for activating polystyrene was attaching amidomethyl group to benzene from polystyrene through reflux process at $65^{\circ} \mathrm{C}$ so that gaining AMDP compound in the form of a white precipitation that played a role as precursor. The formed precipitation of AMDP was caused by electrophilic-aromatic substitution reaction taking place (depicted in Figure 2).

The AMD precipitation that has acyl group must be eliminated to remove acyl group because if this was not conducted, it would have been able to cause the derivative of carboxylic acid easy to encounter nucleophilic substitution. When the reflux was on going at $110^{\circ} \mathrm{C}$, the formation of AMP occurred through hydrolysis reaction of amide so that acetyl group was replaced by other groups which were basic such as amine shown in Figure 3. Elimination of acyl group to AMDP resulted the white MAP resin.

\section{Characterization using Fourier Transform-InfraRed}

Analysis by using FTIR to the result of AMDP indicated spectrums shown in Figure 4.

Of the interpretation result, the data showed that the formation of AMDP in this study was formed due to being resulted the specific spectrum at wavelength number absorption $3418.88 \mathrm{~cm}^{-1}$ (1 band) which was secondary amide group (-NH-) that was bound on benzene from polystyrene, and at wavelength number $1716.68 \mathrm{~cm}^{-1}$ which was characteristic of the present of carbonyl group $(\mathrm{C}=\mathrm{O})$. 


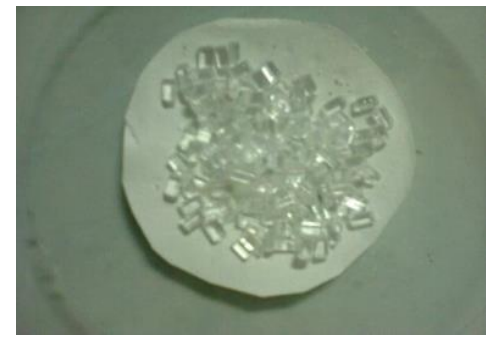

(a)

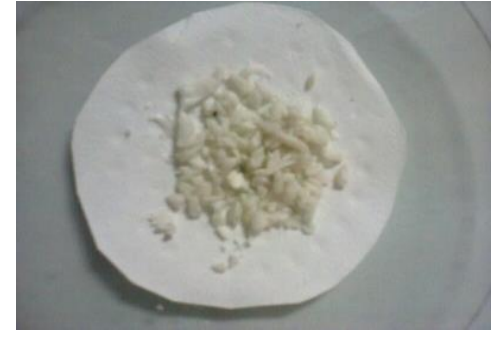

(b)

Figure 1. (a) Polystyrene resin before synthesis.

(b) The synthesis result of MAP resin.
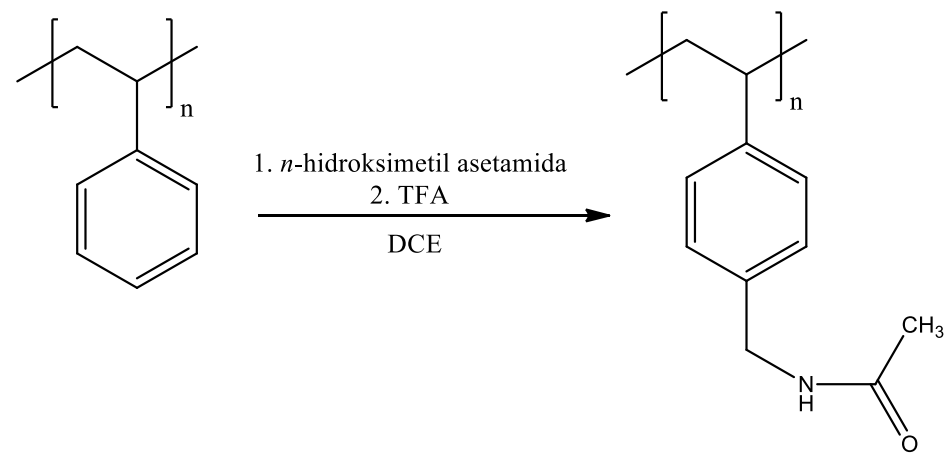

Figure 2. The formation reaction of AMP [2].

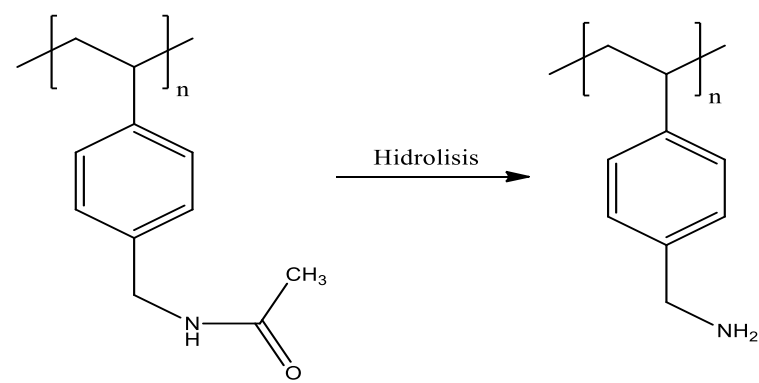

Figure 3. Hydrolysis reaction of acyl group [2].

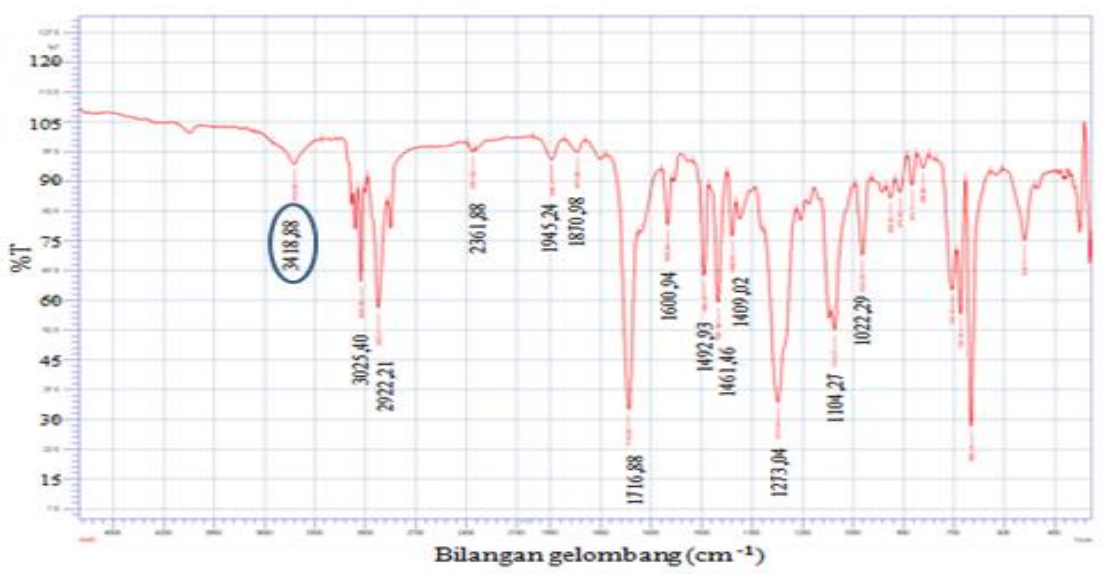

Figure 4. Spectrum of FTIR characterization for AMDP. 
Table 1. Interpretation data of FTIR result for AMDP.

\begin{tabular}{llcc}
\hline \multicolumn{1}{c}{$\left(\mathrm{cm}^{-1}\right)$} & Band & Intensity & Allegation \\
\hline 3418,88 & Sharp & medium & stretching N-H (amida 2 $\left.{ }^{\circ}\right)$ \\
3025,40 & Sharp & Strong & stretching C-H (-CH $\left.2^{-}\right)$ \\
2922,21 & Sharp & Strong & stretching C-H (siklik) \\
1716,68 & Sharp & Strong & stretching C=O (C-karbonil) \\
\hline
\end{tabular}

\section{Characterization of MAP using FTIR}

The synthesis result of MAP resulted was next characterized by using FTIR. In this case, FTIR characterization of the synthesis result of MAP was compared to the FTIR spectrums of MAP in Zhang research [6] so that being able to compare typical spectrum on MAP. The FTIR characterization for MAP in Zhang [6] showed that there was amino group binding benzene from polystyrene at wavelength number $3439.67 \mathrm{~cm}^{-1}$ ( 2 bands) shown in Figure 5.

Meanwhile, the result of FTIR characterization for MAP in this study showed spectrums like in Figure 6.

Of the characterization results, the typical spectrums of MAP were found at wavelength number absorption 3374.52 $\mathrm{cm}^{-1}$ (2 bands) which indicated that the primary amine $\left(1^{\circ}\right)$ bound on polystyrene, and disappearance of band at wavelength $1716,68 \mathrm{~cm}^{-1}$ indicated that there was no $\mathrm{C}=\mathrm{O}$ group on the MAP compound.

\section{Characterization of polystyrene using spectrophotometer UV}

Analysis by using spectrophotometer to polystyrene that has not been activated indicated the curve shown in Figure 7.

The characterization result of polystyrene generated the highest peak at maximum wavelength $221 \mathrm{~nm}$ with absorbance 0.321 that is a consequence of electron transition process from orbital $\pi \rightarrow \pi^{*}$ due to $\mathrm{C}-\mathrm{H}$ double bond on aromatic.

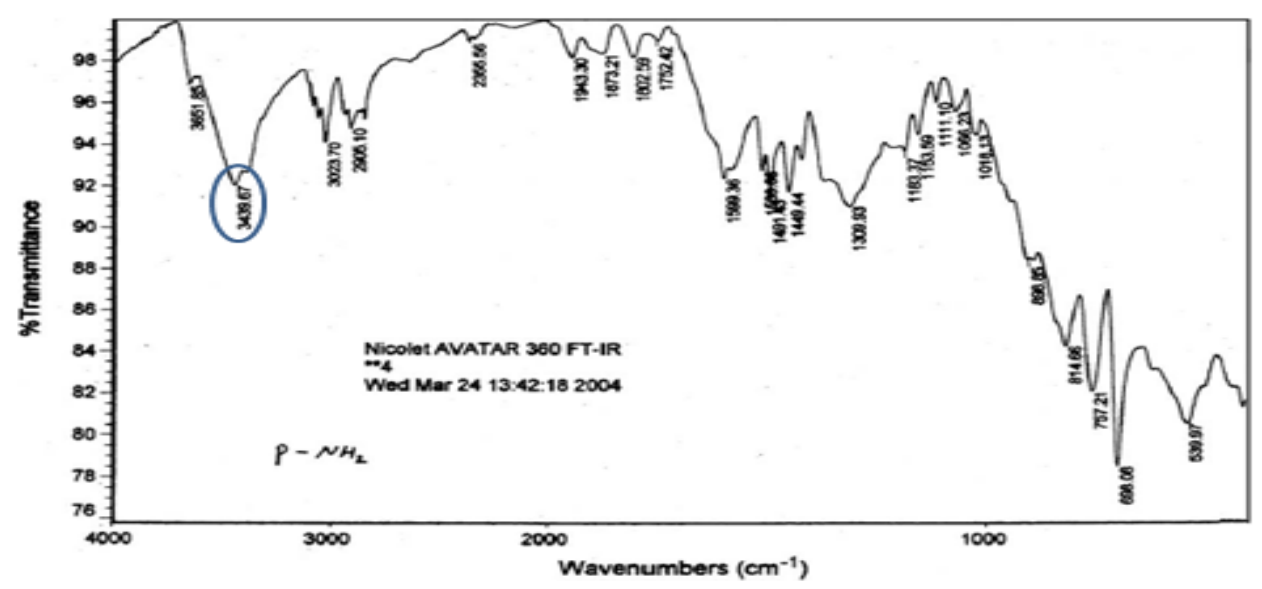

Figure 5. Spectrum of the FTIR characterization for MAP [6]. 


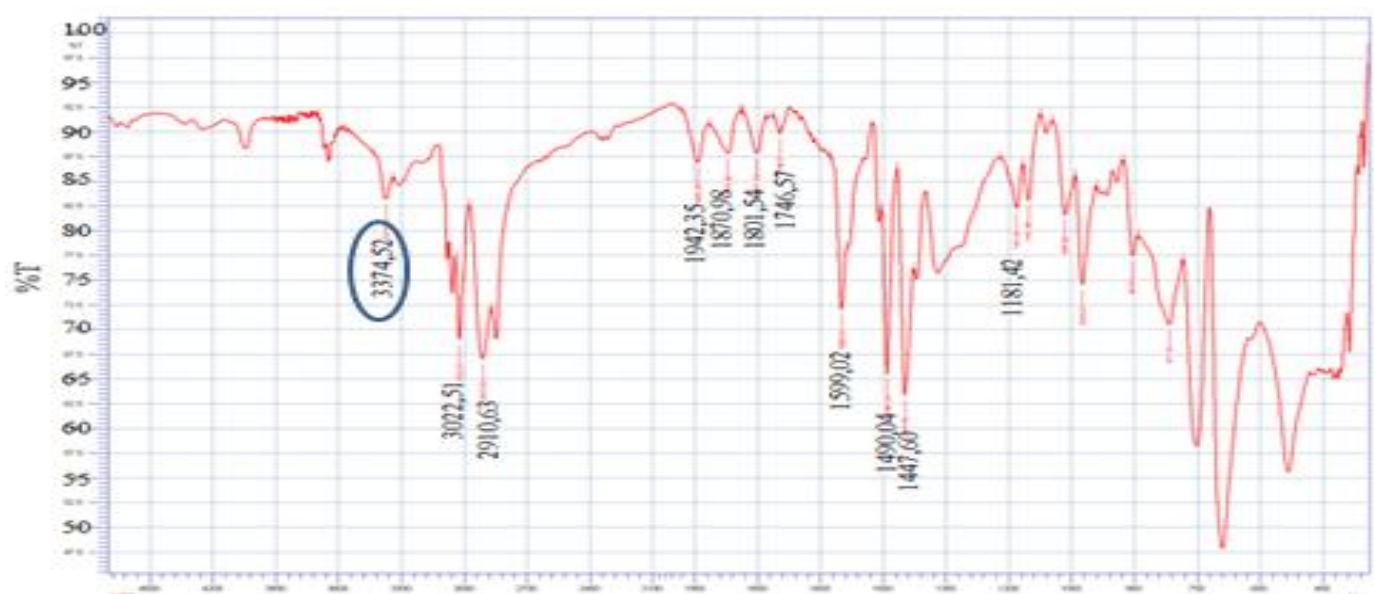

Figure 6. Spectrum of FTIR characterization for the result of MAP synthesis.

Table 2. Interpretation data of FTIR result for MAP.

\begin{tabular}{cccc}
\hline$v\left(\mathrm{~cm}^{-1}\right)$ & Band & Intensity & Allegation \\
\hline 3374,52 & Sharp & medium & Stretching N-H (-NH $\left.2^{-}\right) 1^{\circ}$ \\
3022,51 & Sharp & Strong & Stretching C-H (-CH $\left.2^{-}\right)$ \\
2910,63 & Sharp & Strong & Stretching C-H (-CH-) \\
1599,02 & Sharp & Strong & Bending N-H (2 $)$ \\
1024,22 & Sharp & medium & Stretching C-N (Amina) \\
\hline
\end{tabular}

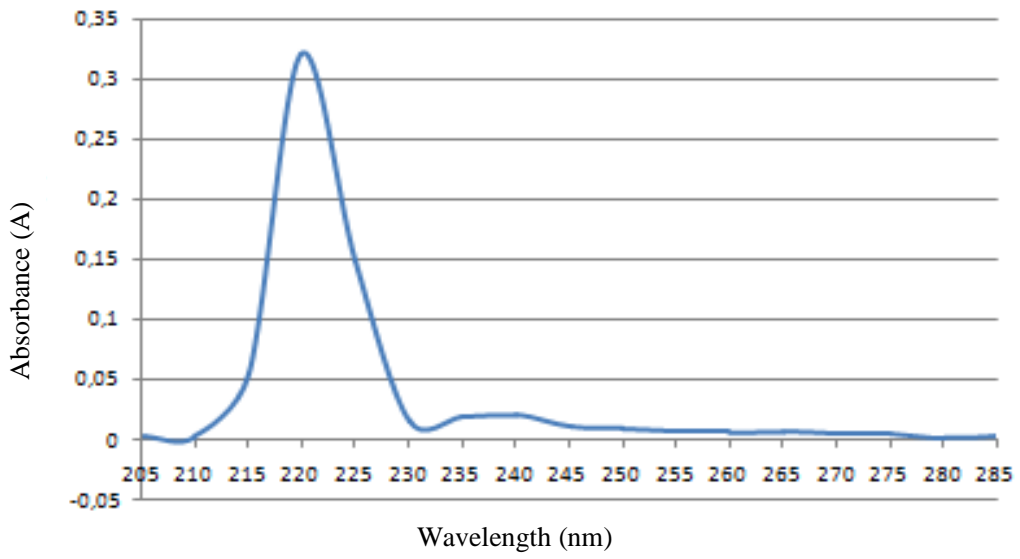

Figure 7. The characterization of spectrophotometer UV for polystyrene. 


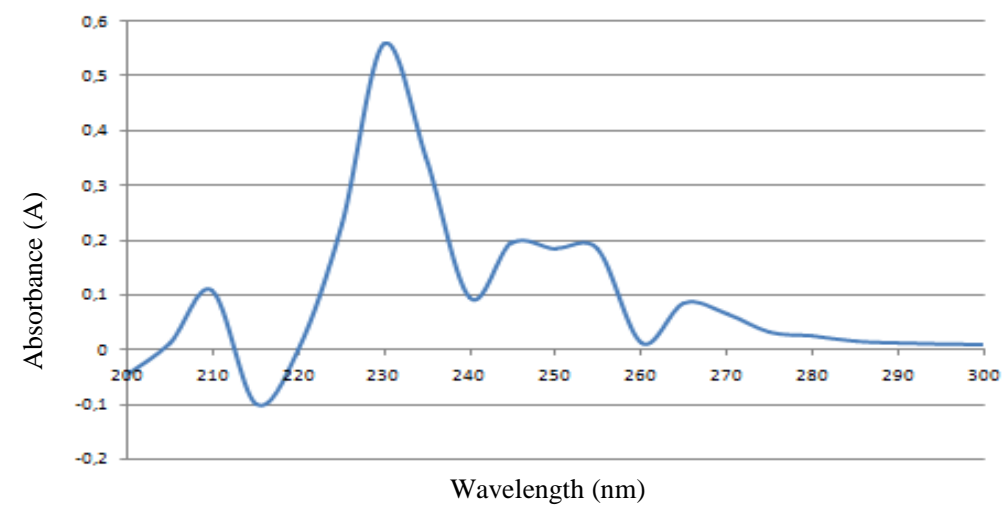

Figure 8. The characterization of Spectrophotometer UV for MAP.

Table 3. The data of determination of MAP resin density

\begin{tabular}{|l|c|c|c|}
\hline \multicolumn{4}{|c|}{ The determination of resin density } \\
\hline & Experiment 1 & Experiment 2 & mean \\
\hline The empty pycnometer & $16.1515 \mathrm{~g}$ & $16.1516 \mathrm{~g}$ & $16.1516 \mathrm{~g}$ \\
\hline Pycnometer + water & $24.0450 \mathrm{~g}$ & $24.346 \mathrm{~g}$ & $24.1955 \mathrm{~g}$ \\
\hline Pycnometer + resin & $16.9852 \mathrm{~g}$ & $16.9853 \mathrm{~g}$ & $16.9853 \mathrm{~g}$ \\
\hline Pycnometer + resin + water & $24.5449 \mathrm{~g}$ & $24.5448 \mathrm{~g}$ & $24.5449 \mathrm{~g}$ \\
\hline \multicolumn{4}{|c|}{ The average of density: $1.7158 \mathrm{~g} / \mathrm{mL}$} \\
\hline
\end{tabular}

\section{The characterization of MAP using spectrophotometer UV}

Analysis by using spectrophotometer UV to polystyrene that has been activated to be AMP showed curve shown in Figure 8 .

The characterization result of MAP generated the highest peak at maximum wavelength $230 \mathrm{~nm}$ with absorbance 0.560 that is a consequence of electron transition process from orbital $n \rightarrow \sigma^{*}$ due to quiet electron on nitrogen heteroatom from $\mathrm{N}-\mathrm{H}$ bond $\left(-\mathrm{NH}_{2}\right)$. Transition $n \rightarrow \sigma^{*}$ occurred required the small energy. If the analysis result between polystyrene that has not been activated compared to polystyrene that has been activated, i.e. MAP, so MAP has resulted the presence of shift of wavelength that was not big enough. This was because of the formation of new bond to the benzene ring from polystyrene, i.e. methyl-amino bond.

\section{Density of MAP resin}

The determination of MAP resin density shown in Table 3.

Table 3 showed that MAP resin of DVB1 polystyrene has density 1.7158 $\mathrm{g} / \mathrm{mL}$. Meanwhile, water (in same temperature) has the density $0.9968 \mathrm{~g} / \mathrm{mL}$. MAP resin has higher density than water. Based on Haddad [5], the developing resin should have higher density than water.

\section{CONCLUSION}

Polystyrene could be activated being methyl amino polystyrene so forming a white MAP resin and being characterized using Fourier TransformInfraRed (FTIR) and Spectrophotometer $\mathrm{UV}$ in which it indicated the formation of amino group at $3374.52 \mathrm{~cm}^{-1}$ with $\lambda_{\max } 230$ $\mathrm{nm}$ which was $\mathrm{N}-\mathrm{H}$ bond $\left(-\mathrm{NH}_{2}\right)$. The average density of the sample of MAP resin was $1.7158 \mathrm{~g} / \mathrm{mL}$. 


\section{REFERENCES}

[1] Anggraeni, A., E. Aghnia M., Sofyatin, T., Hendrati, D., Bahti, H. H. 2017. Preparation of Phosphonated Cation Exchanger Resins and The Exchange Efficiency of Rare Earth Elements, Jurnal Sains dan Terapan Kimia, Volume 11, No. 2 (Juli 2017), 4551

[2] Lee, Y. S., S. J., Ryoo \& T. K., Lee. 2008. Aminomethyl Polystyrene Resin and Preparation Process for the Same. United States Patent US 7,442,745B2.

[3] Fathy, M., T. A. Moghny., M. A. Mousa., A. H. A. A. El-Bellihi., \& A. E. Awadallah. 2015. Sulfonated Ion Exchange Polystyrene composite Resin For Calcium Hardness Removal. International Journal of Emerging Technology and Advanced Engineering, Volume 5, Issue 11, November 2015.
[4] Fathy, M., M. A. Mousa., T. A. Moghny., A. Hameed., E. Bellihi., \& A. E. Awadallah. 2016. Novel Synthesis of Chloromethyl Functionalized Waste Polystyrene or Amorphous Carbon Thin Film Composite Resin. Int. J. Sci.: 14(3), 2016, 1243-1250. ISSN 0972-768 $X$.

[5] Haddad, P. R. \& P. E .Jackson. 1994. Ion Chromatography: Principles and Applications. Elsevier. New York.

[6] Zhang, Q., Shouxin, W., \& Ziqiang, Lei. 2006. Heterogeneous BaeyerVilliger Oxidation of Ketones using Hydrogen Peroxide as Oxidant Catalyzed by Aminomethyl Polystyrene resin Supported Tin Complex. $Q$. Zhang et al. $L$ Reactive \& Functional Polymers 66 (2006) 1278-1283. 